\title{
El cine mexicano en el mundo globalizado: tan lejos de Dios y tan cerca de Estados Unidos
}

\author{
Fernando Moreno Suárez \\ (Universidad Iberoamericana) \\ Recibido:24/1/2013 \\ aprobado: $28 / 2 / 2013$
}

Resumen: En 1997, la cinematografía mexicana tuvo una baja histórica con una producción de solo nueve películas. El año 2007 significa un crecimiento sin igual de setenta películas realizadas y siete mexicanos nominados al Óscar. En un patrón sin precedentes para una economía neoliberal, del 2008 al 2010 más del $80 \%$ de la producción es financiada por el gobierno, mientras que en 1982 apenas un 10 \% seguía esa línea. El crecimiento del apoyo gubernamental ha incrementado el número de producciones y de premios internacionales, pero ha creado una serie de situaciones irregulares en el mercado: películas producidas pero apenas distribuidas, y una subordinación significativa en contra de la dominación de Hollywood.

Palabras clave: Cine mexicano / globalización / mainstream

\section{Mexican cinema in the globalized world: so far from God and so close to the United States}

AвSTRACT: In 1997, the Mexican filmography had a historical low with a production of only nine films. 2007 reaches a new high of seventy films produced and seven Mexicans nominated in the Academy Awards. In an unexpected pattern for a neoliberal economy, from 2008-2010 more than $80 \%$ of the production is government-supported, whereas roughly $10 \%$ of the production followed that pattern in 1982. A growing state support has increased the number of productions and of international awards received by the films, but has created a number of irregular behaviors in the market: films being produced but hardly distributed, and a significant subordination against the domination of Hollywood.

Keywords: Mexican cinema / globalization / mainstream 
La 'globalización' está en boca de todo el mundo; una palabra de moda que se está convirtiendo rápidamente en una consigna, en un conjuro mágico, en una llave maestra destinada a abrir las puertas de todos los misterios presentes y futuros.

Zygmunt Bauman, Globalization: the HUMAN CONSEQUENCES

\section{Introducción}

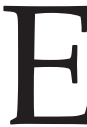
125 de febrero del 2007, en el Kodak Theater de Hollywood se entregaban los premios de la Academia de Artes y Ciencias Cinematográficas en su septuagésima novena edición. En una ceremonia marcada por el reconocimiento tardío de Hollywood a Martin Scorsese, las múltiples nominaciones de personajes de origen latino generarían un impacto mediático internacional en la carrera de muchos de los presentes, aún en aquellos que no se llevaran el Óscar a su casa esa noche. Entre los nominados, la presencia de los mexicanos Alejandro González Iñárritu, Guillermo del Toro, Adriana Barraza, Guillermo Arriaga, Eugenio Caballero, Emmanuel Lubezki o Guillermo Navarro, representaban la manifestación más clara del encumbramiento de directores, actores y técnicos aztecas en la meca del cine. Paralelo a esto, y tal vez como consecuencia de esta buena reputación internacional, la producción nacional se fortalecía, se aprobaban estímulos fiscales para la industria y los números reportados por las instituciones oficiales permitían pensar en un escenario favorable en el futuro.

Poco tiempo después, el Instituto Mexicano de Cinematografía (Imcine) publicaba una serie de datos que revelaban un aumento considerable en la producción cinematográfica nacional. Situación que sumada al hecho de que es cada vez más notoria la presencia de talento mexicano en diversos eventos internacionales, parecía dar señas de una revalorización del cine mexicano en el concierto internacional. Paradójicamente, las leyes del mercado y los números de las películas mexicanas en nuestra propia taquilla, la quinta más importante del mundo, son poco halagadores. Con la reserva de desarrollarlo en detalle más adelante, resulta dramático saber que, aunque se ha reactivado la producción de manera importante, en el 2010 solo el $6 \%$ de la taquilla es para el cine nacional y, en lo que respecta a cuotas de pantalla, tampoco salimos bien librados frente al poder de los estudios norteamericanos al contar con un pírrico $16 \%$. Como dato introductorio es importante señalar que hoy hay 4818 pantallas en el país y que una película grande de la industria hollywoodense se estrena con 1500 copias normalmente, ante las 350 de los estrenos nacionales más ambiciosos. Un dato más para completar el panorama: de los 318 estrenos del año pasado, 175 
fueron norteamericanos, con una recaudación que alcanzó el $91 \%$ de los ingresos en taquilla (Imcine 2010).

Frente a esto surgen muchas interrogantes: ¿Se puede considerar como mexicano el cine que hacen "Los Tres Amigos" y los demás técnicos exitosos en el extranjero? ¿Puede el cine nacional hacer frente a Hollywood y su dominio en el concierto de una cinematografía global? ¿Cómo competir, desde una industria incipiente, con el poder hegemónico cultural de los majors? ¿Qué hacer en materia de distribución y exhibición? ¿Cómo hacer que en nuestras propias salas se vea cine mexicano? De eso precisamente versará este ensayo que, lejos de proponer respuestas exactas, busca reflexionar sobre un arte industrial complejo. En estos tiempos de «globalización», resulta útil recordar las palabras del investigador argentino radicado en México Néstor García Canclini, y entender que vivimos «[...] un proceso de interdependencia entre todos los países y todas las culturas, que incluye la economía, las finanzas, las comunicaciones y todos los aspectos socioculturales» (García Canclini 2008).

\section{El cine mexicano frente al mundo. Pasado y presente}

La historia del cine en México parece una metáfora de nuestra relación bilateral de vecindad con el país más poderoso del mundo, con el imperio que nos ha tocado vivir y sufrir a los que nacimos a finales del siglo pasado: Estados Unidos.

Si bien es cierto que el cinematógrafo nos llegó de Francia y que la patente le pertenece a los hermanos Lumière, el desarrollo del cine mexicano siempre ha dependido de lo que pasa al norte de nuestra frontera. Tal vez la única excepción sea el propio nacimiento del cine en nuestro país con la llegada de los enviados de la casa Lumière, Gabriel Veyre y Claude Ferdinand Von Bernard, que la noche del 6 de agosto de 1896 proyectaban la primera película al presidente Porfirio Díaz, su familia y miembros de su gabinete en uno de los salones del castillo de Chapultepec. Después de eso, y de una aceptación discreta, el momento histórico más relevante en la primera mitad del siglo XX tiene que ver con Estados Unidos y una coyuntura histórica en lo que se conoció como la «Época de Oro del cine mexicano». Durante esta, y aprovechando que Hollywood no producía normalmente por su participación en la Segunda Guerra Mundial, se desarrolló en México una industria que producía más de cien películas al año, llegando a su punto más alto en 1959 con la cifra récord de 135 (Imcine 2010). Estas cintas se exportaban a mercados de Latinoamérica y Europa, generando no solo una imagen de país hacia el extranjero, sino construyendo también una idea de nacionalidad. En este sentido, no es aventurado afirmar que, junto con el movimiento muralista encabezado por Diego 
Rivera, David Alfaro Siqueiros y José Clemente Orozco, la época de oro del cine mexicano constituye un referente fundamental en la alfabetización visual, artística y simbólica de una nación que migraba del campo a la ciudad. En suma, el cine se traducía en un elemento de identidad cultural tal y como lo sugieren Gilberto Giménez (2007) y Jesús Martín Barbero (2002).

En el aspecto económico, y siguiendo todos los paradigmas fordistas que en Hollywood habían convertido a los estudios de cine en fábricas que generaban en serie productos culturales para su consumo, la época de oro significa, según Carlos Monsivais (1993: 9-13) el desarrollo de nuestro propio star system (sirvan como ejemplo para ilustrar esto personalidades de la talla de Cantinflas, Pedro Infante, Jorge Negrete o María Félix) y el encumbramiento internacional de decenas de directores que iniciaron o continuaron su carrera en este periodo histórico, como Emilio Fernández, Andrés Soler, Luis Buñuel, Fernando de Fuentes o Ismael Rodríguez.

Después de este momento, como explica de nuevo Monsivais (1993: 101), poco hay que contar en la historia del cine azteca, que pierde fuerza, capital y presencia al regresar Hollywood por los espacios y mercados que consideraba suyos y que toca fondo definitivamente en 1997, con la producción de tan solo nueve películas (Imcine 2010).

Recientemente, la situación del cine nacional está llamando la atención, y muestra de ello son los datos arrojados por el Imcine (2007a) en su «Informe de labores», que revelan que la producción de películas mexicanas en el 2007 fue la más alta en diecisiete años, con un total de setenta filmes, $10 \%$ más que el año anterior, promedio que se ha mantenido en la producción de los tres siguientes años.

Gráfico 1

Producción de películas mexicanas 1990-2007

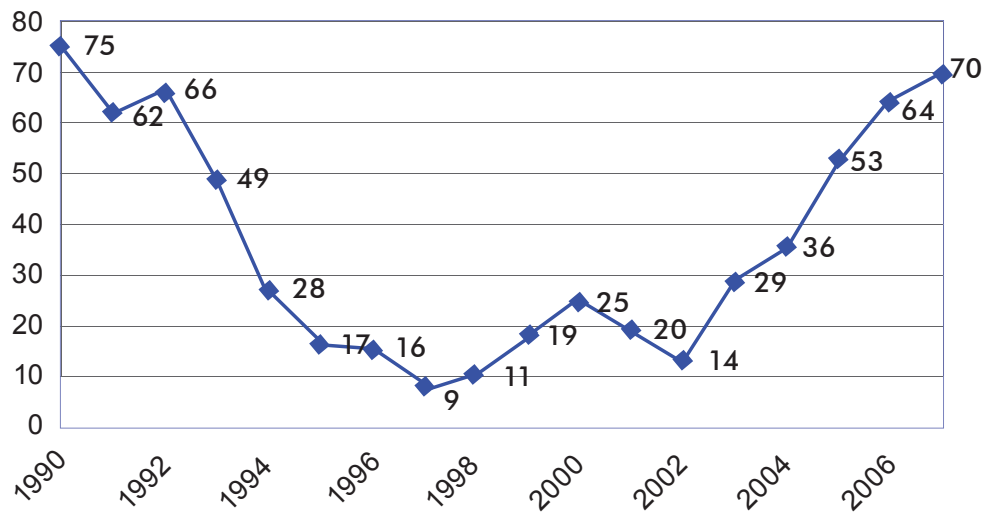

Fuente: Instituto Mexicano de Cinematografía. Informe de Labores 2007. México, 2007. 


\section{Gráfico 2}

Apoyo del Estado a la producción cinematográfica

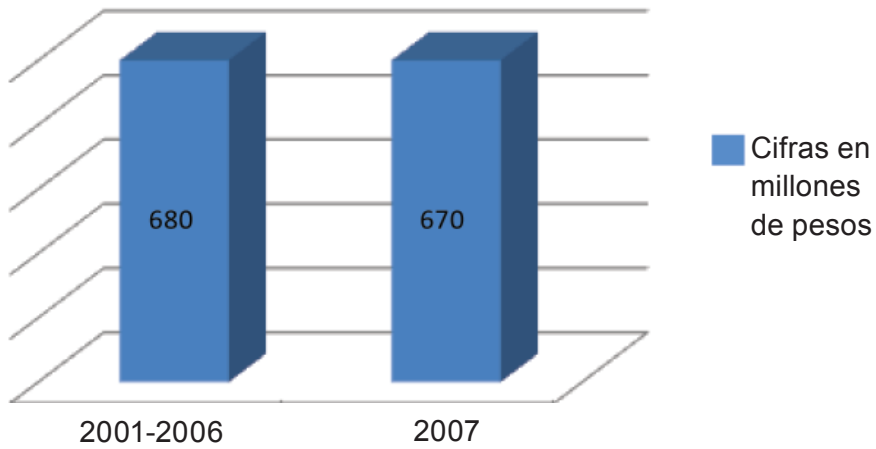

Fuente: Instituto Mexicano de Cinematografía. Informe de Labores 2007. México, 2007.

Ante el nuevo panorama todo parecería miel sobre hojuelas, pero los focos rojos se encienden en cuanto llegamos al terreno de la distribución y exhibición. Según los Informes de Labores del Imcine $(2007,2010)$, en el 2007 solo se estrenaron 43 películas mexicanas de las setenta producidas, de las cuales el $79 \%$ contaron para su producción con recursos públicos. Para el 2010 hay una discreta mejora con el estreno de 56 de los 69 largometrajes nacionales producidos.

El tema de la distribución enfrenta, de manera global, una tendencia hacia el oligopolio, lo que también afecta a la distribución en México. Tal y como lo señala Castells:

En la primera edición de su libro pionero, The Media Monopoly, Ben Bagdikian identificó cincuenta empresas que dominaban el mercado estadounidense de los medios de comunicación. Sucesivas ediciones revisadas del libro mostraban un número decreciente de compañías dominantes: 29 empresas en 1987, 23 en 1990, 10 en 1997, seis en 2000 y cinco en 2004. Si bien Bagdikian se centraba en Estados Unidos, la misma tendencia puede observarse en todo el mundo. Por ejemplo, en 2006, Disney, Time Warner, NBC Universal, Fox Studios (News Corp) y Viacom representaban el 79\% de la producción cinematográfica y el $55 \%$ de la distribución mundial (2009: 113 y 114).

Por su parte, Sánchez Ruiz afirma que:

Ante las políticas «neoliberales», que se supone han dejado al sector a merced de las «leyes» de la oferta y la demanda, la situación que presenta actualmente la industria cinematográfica nacional se ha traducido en tres principales rasgos: a) un proceso casi inexorable de contracción, en particular de la producción nacional; b) otro de concentración en unas pocas empresas, tanto de la producción como 
de la distribución y la exhibición, y c) una acelerada transnacionalización, es decir, una cada vez mayor articulación subordinada y receptiva al mercado mundial, a su vez dominado por la industria cultural más poderosa del mundo, la de Estados Unidos (1998: 57).

Paradójicamente, y con relación a esa trasnacionalización de la que habla Sánchez Ruiz, es relevante señalar el sonado fracaso de los intentos de Columbia Pictures y Warner Brothers al abrir oficinas de producción en nuestro país.

Otro dato dramático para completar el panorama: solo el $8 \%$ de los espectadores se decantaron en el 2007 por el cine mexicano, pasando de 11 millones en el 2006 a 14 millones de espectadores este año. El $91 \%$ de los ingresos son para las producciones de los grandes estudios norteamericanos que, literalmente, aplastan en su primera semana en cartelera a cualquier producción nacional o independiente (Imcine 2010).

Sánchez Ruiz afirma que en México, desafortunadamente, no se han estudiado de manera sistemática y empírica los públicos del cine y que este lapso apenas comienza a ser $\mathrm{cu}^{-}$ bierto:

Creemos que las investigaciones que dirigió Néstor García Canclini a principios de los noventa, financiadas por el Instituto Mexicano de Cinematografía (Imcine) y el Consejo

Gráfico 3

Películas mexicanas estrenadas en cartelera comercial (1995-2007)

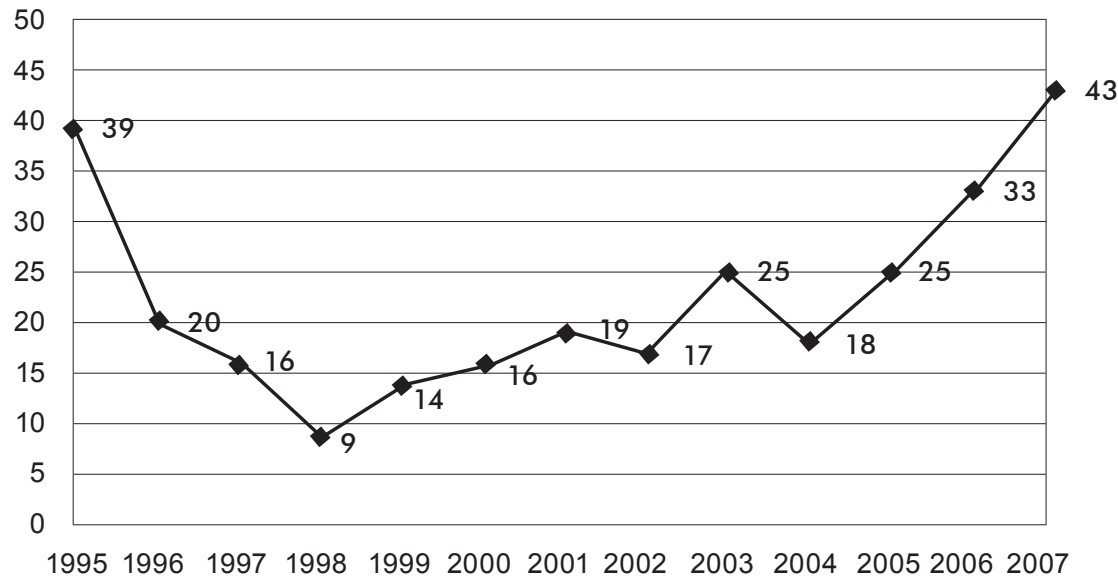

Fuente: Instituto Mexicano de Cinematografía. Informe de Labores 2007. México, 2007. 
Nacional para la Cultura y las Artes (Conaculta), son pioneras en este campo. Los datos descriptivos empíricos con que contamos corroboran que la demanda por los productos culturales cinematográficos se ha ido acomodando en los últimos años a la oferta, en particular en términos de las películas que prefiere y que efectivamente ve la gente, tanto en las salas cinematográficas, como en las videocaseteras y en la televisión (1998: 76).
Al respecto, llama la atención la reciente publicación del Imcine en la «Encuesta nacional de consumo y percepción de cine mexicano» (2010), donde ocho de cada diez entrevistados declaró ver cine mexicano por lo menos una vez por semana. Ante el optimismo de tal cifra, el dato fino nos lleva al desencanto, ya que el $75 \%$ lo consume por televisión abierta, $50 \%$ por televisión de paga y $30 \%$ declaran rentar películas o comprarlas tanto en el mercado formal como en la piratería.

\section{Gráfico 4}

Asistentes a ver cine mexicano (2001-2007)

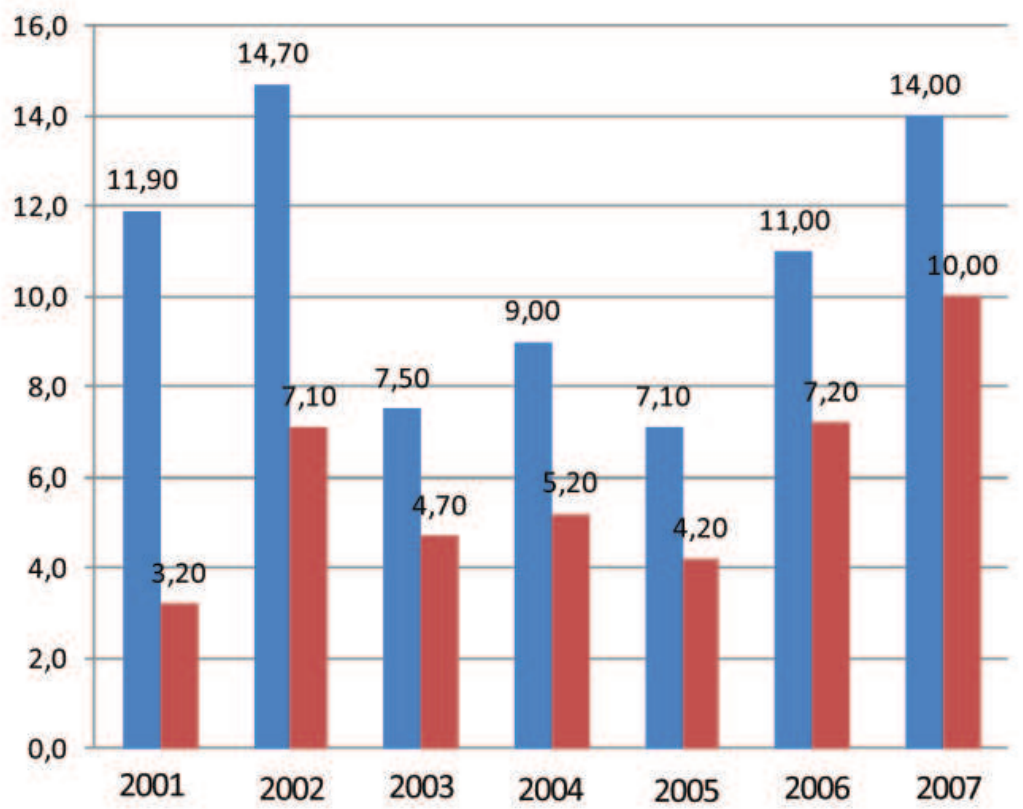

Asistentes a ver cine mexicano (millones)

= Asistentes a ver cine mexicano apoyado por el Estado (millones)

Fuente: Instituto Mexicano de Cinematografía. Informe de Labores 2007. México, 2007. 
Por otro lado, la lógica de los exhibidores es muy simple: si una cinta no vende un número determinado de boletos el primer fin de semana desaparece de las marquesinas. A este fenómeno se le conoce en el medio cinematográfico como un "semanazo», que estrictamente significa que la película pequeña que no supere tres días de exhibición consuma su fracaso comercial. Además, tal y como lo señala Castells: «Incluso la industria del cine, que históricamente confiaba en los ingresos en taquilla, depende cada vez más del merchandising y las promociones cruzadas» (2009: 139).

Continuando con los números, un aspecto más a tomar en cuenta para entender el resurgimiento en la producción en México tiene que ver también con lo económico y con un estímulo fiscal reciente: el artículo $226{ }^{1}$ Hace dos años el Congreso mexicano aprobó incorporar a la Ley del Impuesto sobre la Renta el artículo 226, que ofrece un estímulo fiscal que le permite acreditar a cualquier empresa o persona que invierta en la producción de cine nacional hasta un $10 \%$ del impuesto sobre la renta. La disposición contempló hasta 500 millones de pesos de techo fiscal, que se ejercieron en su totalidad en la producción de cintas. Esto es, se inyectaron más de 50 millones de dólares a la producción que no venían de los recursos del Estado.

Hollywood y sus temas, el mercado y su lógica, Estados Unidos y su idioma - al igual que los imperios de toda la historia con sus modelos y sus paradigmas - marcan hoy el paso al que se mueven los demás actores de la industria del entretenimiento global. El mainstream controla casi en su totalidad los canales de distribución y exhibición ejerciendo el poder. Al margen de su dominación, y tal vez gracias a ella, se mueve un cine independiente que al resistirse a su lógica y sistemas de producción parece afirmarlo día tras día al mismo tiempo que lo reta. Siguiendo este punto de vista, vale la pena examinar el trabajo de García Canclini, quien ha propuesto una revisión radical de las políticas culturales mexicanas, y latinoamericanas, para «[...] disminuir los aspectos de la alta cultura y conectar más con la "cultura común" por medio del desarrollo de la cultura popular nacional» (García Canclini 2008).

1 El artículo 226, publicado el 7 de diciembre del 2009 en el diario oficial de la federación, explica que se otorga un estímulo fiscal a los contribuyentes del impuesto sobre la renta, consistente en aplicar un crédito fiscal equivalente al monto que, en el ejercicio fiscal de que se trate, aporten a proyectos de inversión en la producción cinematográfica nacional, contra el impuesto sobre la renta o el impuesto al activo que tengan a su cargo en el ejercicio en el que se determine el crédito. 


\section{Perspectivas de futuro}

Revisar superficialmente la realidad del cine mexicano contemporáneo y sus indicadores numéricos frente a la dominación cultural e ideológica norteamericana parecen invitar a un escenario apocalíptico. Sin embargo, existen varias lecturas posibles, y si se hace un análisis profundo de la realidad se imponen distintas reflexiones.

La primera y más obvia arroja la inevitable verdad de que la globalización es un fenómeno que ya está aquí, independientemente de nuestro gusto o aceptación y sabiendo que se pueden adoptar frente a ella y su inequitativo modelo muchas posiciones. La más sencilla y torpe es la de víctima, la más inteligente y compleja la de contendiente. Este es precisamente el orden de ideas con el que se tratará de concluir este trabajo. En la lógica que hace que un problema nos rete antes que derrotarnos.

La realidad nos condiciona mas no nos determina. Solo desde este enfoque entenderemos que frente al control casi absoluto de Hollywood sobre los canales de exhibición el cine mexicano tiene que trabajar en la creación de nuevos públicos -recuperando las ideas de Martín Barbero (2002) a través del diseño y producción de contenidos más competitivos. Frente a la invasión ideológica de películas homogeneizadoras proponer productos culturalmente auténticos y distintos que vuelvan a manifestarse como referentes de identidad nacional - no tiene ningún sentido intentar hacer lo que hace el imperio desde la periferia, tratar de producir como Hollywood no solo es absurdo sino imposible económicamente, inútil e innecesario-. En este mismo orden de ideas vale la pena recordar, como sostiene Gilberto Giménez (2007), que lo global solo se puede manifestar en lo local y que en esa dinámica lo local puede reafirmarse y fortalecerse. Ante el dominio económico de las superproducciones trabajar para tratar de hacer finalmente rentable al cine nacional. Ante la maquinaria aceitada de los majors luchar para reactivar una incipiente industria en recuperación y encontrar nuevas formas de producción, distribución y financiamiento.

Si bien se reconoce que hoy hay un interés de parte de las autoridades de impulsar el cine, y que es este interés precisamente el que lleva a la promulgación de la Ley 226, también es cierto que este esfuerzo no es suficiente ya que hasta el momento solo ha repercutido en un incremento de la cantidad de películas que se hacen en México y no necesariamente sobre la calidad ni ha garantizado que esas películas se exhiban en condiciones aceptables.

Por otro lado, existe una nueva generación de cineastas que, desde dentro y fuera de México, están haciendo cintas que demuestran que existe el talento y el capital humano para proponer una visión interesante de este mundo posmoderno y global desde un 
país que tiene muchísimos años tratando de alcanzar la mayoría de edad económica y políticamente.

Permeado por esas fuerzas del mercado, el título que da nombre a este texto tiene relación con una frase atribuida a Porfirio Díaz al partir a su exilio en Francia: «Pobre México. Tan lejos de Dios y tan cerca de los Estados Unidos», que parece definir en muchos aspectos no solo las limitaciones de la política cultural de nuestro país, sino una serie de vicios que se repiten de manera cíclica en las mecánicas de nuestra incipiente industria cinematográfica. Más allá del sarcasmo y la ironía del dicho popular, queda la necesidad de trabajar para que cada día este sea menos cierto.

Las asignaturas pendientes son muy claras: reconstruir la industria; producir más y mejor; generar condiciones mejores y más justas de exhibición y distribución; alfabetizar mediática y cinematográficamente; y trabajar en la creación y recuperación de públicos y mercados tanto dentro como fuera de nuestras fronteras se imponen como tareas inaplazables. Solo así empezaremos a aprovechar la globalización en lugar de padecerla.

\section{Bibliografía}

Arteaga, Nelson; Masse, Carlo y Pablo Castro (2006). Actores y poderes locales en la globalización. México: Universidad Nacional Autónoma de
México, Facultad de Ciencias Políticas y Administración Pública.

Beck, Ulrich (2008). ¿Qué es la globalización? Falacias del globalismo, respuestas a la globalización. Barcelona: Paidós.

Castells, Manuel (2009). Comunicación y poder. Madrid: Alianza.

García Canclini, Néstor (2008). Entrevista personal.

García Canclini, Néstor y Enrique Sánchez Ruiz (comp.) (2006). Situación actual y perspectivas de la industria cinematográfica en México y en el extranjero. Guadalajara: Universidad de Guadalajara, Instituto Mexicano de Cinematografía.

García Canclini, Néstor (1999). La globalización imaginada. México: Paidós.

García Canclini, Néstor (1994). De lo local a lo global: perspectivas desde la antropología. México: Universidad Autónoma Metropolitana, Unidad Iztapalapa, División de Ciencias Sociales y Humanidades, Departamento de Antropología.

Giménez, Gilberto (2007). Estudios sobre la cultura y las identidades sociales. México: Conaculta.

Gubern, Román. (2008) Entrevista personal.

Ianni, Octavio (2002). Teorías de la globalización. México: Fondo de Cultura Económica.

Imcine (Instituto Mexicano de Cinematografía) (2010). Anuario estadístico de cine mexicano 2010. México. 
$<$ http://www.imcine.gob.mx/anuario-estadstico-2010.html>.

Imcine (Instituto Mexicano de Cinematografía) (2007a). Informe de Labores 2007. México.

Imcine (Instituto Mexicano de Cinematografía) (2007b). Indicadores por Sector de la Industria Cinematográfica en México, 2002-2007. México. $<$ http://www.imcine.gob.mx/IMCINE/SALA/pdf/2002_2007.pdf>.

Martel, Frederic (2011). Cultura mainstream. Madrid: Taurus.

Martín Barbero, Jesús (2002). Oficio de cartógrafo. Travesías latinoamericanas de la comunicación en la cultura. México: Fondo de Cultura Económica.

Mattelart, Armand (2007). Historia de la sociedad de la información. Barcelona: Paidós.

Monsivais, Carlos (1993). Rostros del cine mexicano. México: Américo Arte Editores.

Sánchez Ruiz, Enrique (mayo-agosto de 1998). «Cine y globalización en México. El desplome de una industria cultural». Comunicación y Sociedad 33. Guadalajara: Universidad de Guadalajara, DECS, pp. 47-91. 